\title{
A Personal Recollection Of Four Years Work In The Crown Lynn Design Studio From 1978 To 1982
}

Juliet Hawkins

In the last two or three decades many New Zealanders have collected and treasured consumer goods manufactured and often designed in this country in the post-war period. These items are valued not necessarily for their quality but because they were local and symbolic of emergent understandings of national autonomy and distinctiveness. In a time when global corporations flood national markets with low-cost generic goods produced where there is low-cost labour, there is an international movement by 'baby boomer' collectors to conserve items produced in their nations when they were young.

In New Zealand the ceramics produced by Crown Lynn from just before the Second World War until the company closed its factories in 1989, epitomise this desire to collect items we now identify as 'Kiwiana'. Sociologist Claudia Bell identifies these collectors as regarding themselves as custodians "of national treasures; the items are revered as repositories of strands of the national story". ${ }^{1}$ For Bell their collecting of often technologically obsolescent or even crude items of mid-century style is also "a considered act of resistance to globalisation". ${ }^{2}$

Stimulated by wartime shortages and post-war government restrictions on imported goods, Crown Lynn grew to produce a wide range of domestic and industrial ceramics. There is, therefore, diverse choice for the collector of Crown Lynn 
which may account for why the company's products are the most prominent items of Kiwiana collecting.

In 1960 the West Auckland factories were producing around ten million items a year and at its peak in the mid-1970s, more than 500 people were employed at Crown Lynn. ${ }^{3}$ However, by the late 1970s the company's position in the local market was being impacted by the removal of import controls. Juliet Hawkins joined the company's design department in 1979. In this personal reminiscence she recounts her experience with this now iconic producer of local ceramics.

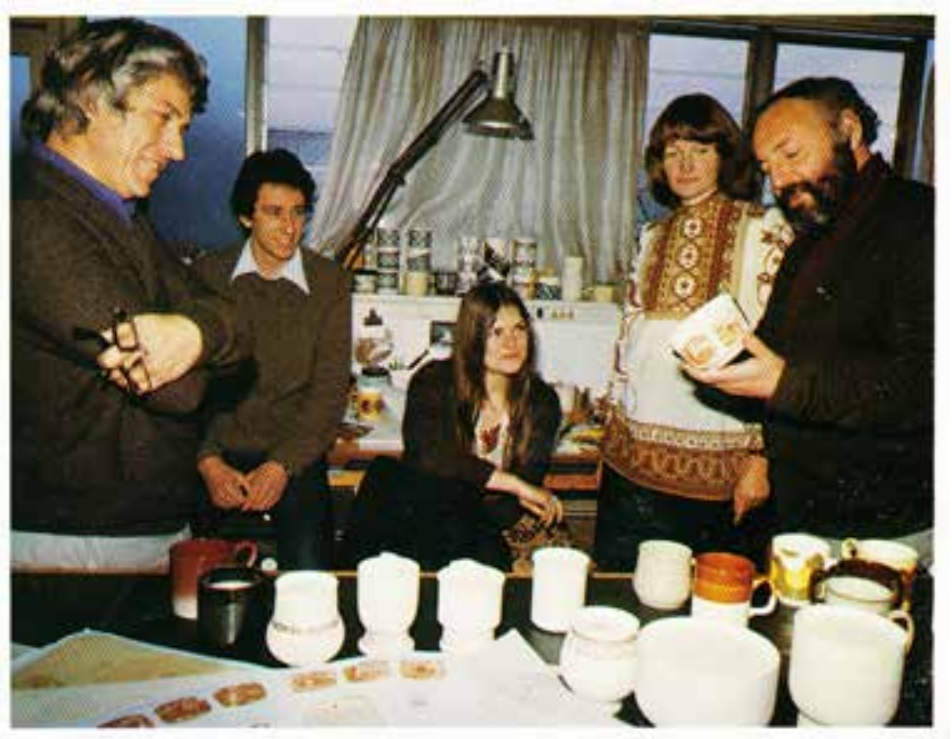

(From L. to R.) Mark Cleverley, Ian McNee, Juliet Hawkins, Jan Scoones \& Tom Arnold in Crown Lynn's Design Studio. Image from the Crown Lynn held by the Crown Lyn huld by the Crown Lynn Museum-Te Toi Uku, Ambrico Place, New Lynn
I graduated from the Auckland Technical Institute (ATI) in 1978 with a diploma in Graphic Design. The three year course provided hands-on techniques from 3D models, clay work, screenprinting and photography to illustration, typography and design. This was all prior to the computer age. At the end of year exhibition, companies, looking for junior employees, were invited to view the work and offered positions to potential candidates. I was fortunate enough to be selected by Dave Jenkin and Mark Cleverley to join the Crown Lynn design team starting immediately. No time for Holidays! This was extremely daunting but exciting at the same time, being my first 'real' job at the age of 19. Dave Jenkin was Chief Designer and Manager of the studio, Mark Cleverley was Development Designer, Jan Scoones and lan McNee were the very talented Design Artists. I had four weeks to learn the processes and to settle in before the factory closed for two weeks over the Christmas break.

Dave and Mark had been working on the 'Earthstone' range since 1977. It was a new 'Resist' (in-glaze) technique using bold earthy patterns - 'Autumn', 'Camille', 'Polynesia', 'Sandown' and 'Landscape'. The colours and glazes were trialled in liaison with Ray Coragen and Reg Taylor in the Colour Lab. Jan and lan produced each colour separation for these new patterns by hand on drafting film, a very time consuming and exacting process. They also continued on with other mug ideas for light relief.

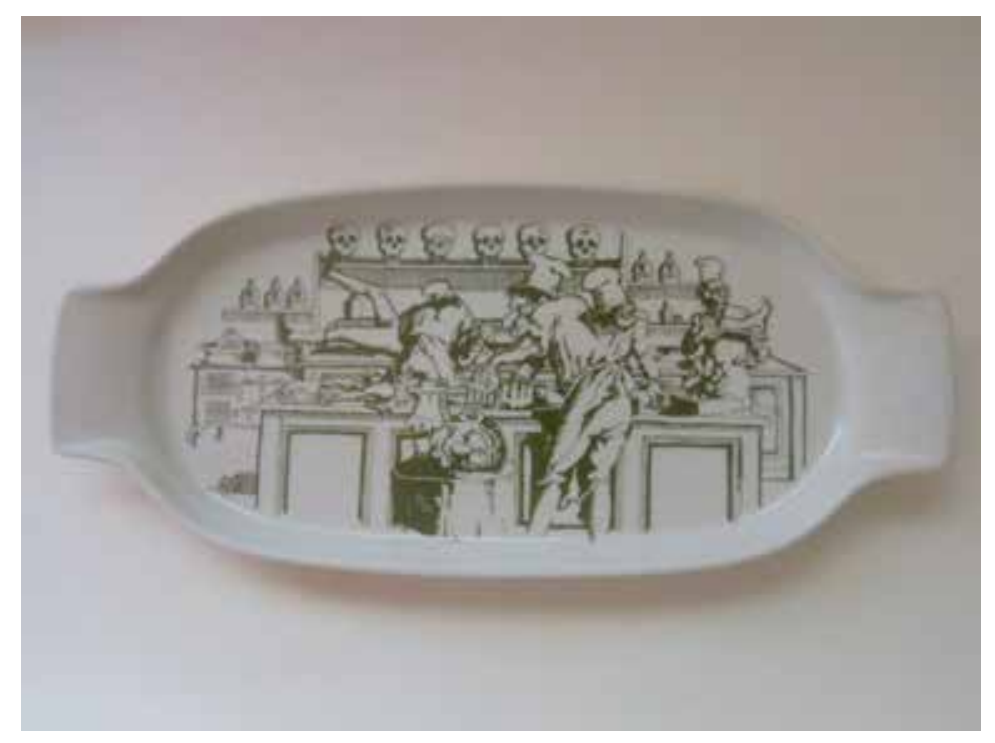

'Cordon Kitchenware', a one-off design by lan $\mathrm{McNee}$ 
which may account for why the company's products are the most prominent items of Kiwiana collecting.

In 1960 the West Auckland factories were producing around ten million items a year and at its peak in the mid-1970s, more than 500 people were employed at Crown Lynn. ${ }^{3}$ However, by the late 1970s the company's position in the local market was being impacted by the removal of import controls. Juliet Hawkins joined the company's design department in 1979. In this personal reminiscence she recounts her experience with this now iconic producer of local ceramics.

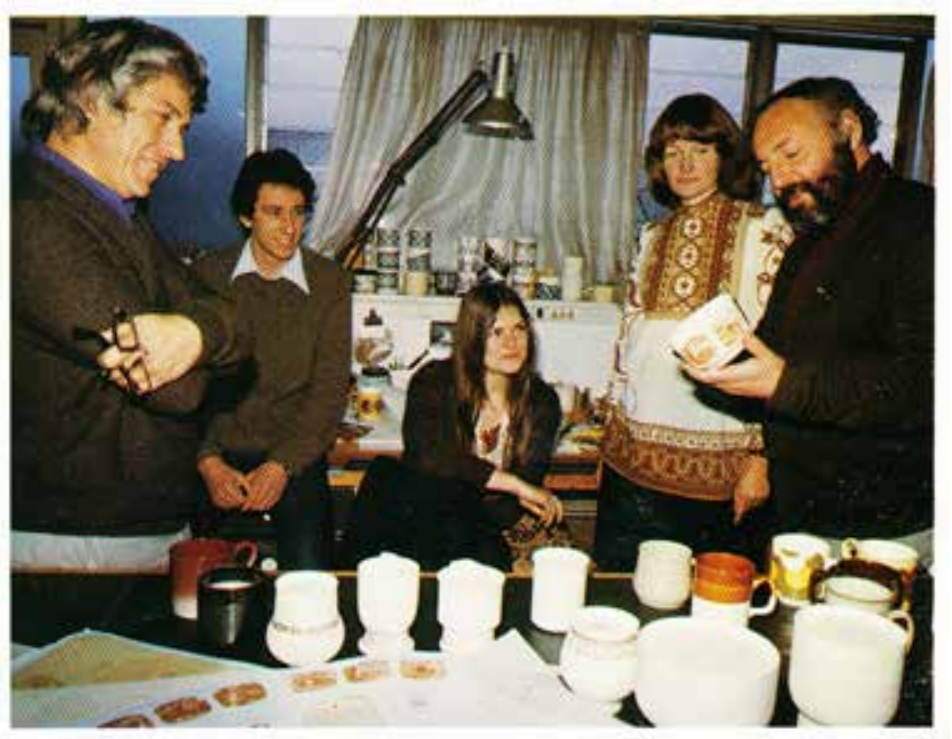

(From L. to R.) Mark Cleverley, Ian McNee, Juliet Hawkins, Jan Scoones \& Tom Arnold in Crown Lynn's Design Studio. Image from the Crown Lynn held by the Crown Lyn huld by the Crown Lynn Museum-Te Toi Uku, Ambrico Place, New Lynn
I graduated from the Auckland Technical Institute (ATI) in 1978 with a diploma in Graphic Design. The three year course provided hands-on techniques from 3D models, clay work, screenprinting and photography to illustration, typography and design. This was all prior to the computer age. At the end of year exhibition, companies, looking for junior employees, were invited to view the work and offered positions to potential candidates. I was fortunate enough to be selected by Dave Jenkin and Mark Cleverley to join the Crown Lynn design team starting immediately. No time for Holidays! This was extremely daunting but exciting at the same time, being my first 'real' job at the age of 19. Dave Jenkin was Chief Designer and Manager of the studio, Mark Cleverley was Development Designer, Jan Scoones and lan McNee were the very talented Design Artists. I had four weeks to learn the processes and to settle in before the factory closed for two weeks over the Christmas break.

Dave and Mark had been working on the 'Earthstone' range since 1977. It was a new 'Resist' (in-glaze) technique using bold earthy patterns - 'Autumn', 'Camille', 'Polynesia', 'Sandown' and 'Landscape'. The colours and glazes were trialled in liaison with Ray Coragen and Reg Taylor in the Colour Lab. Jan and lan produced each colour separation for these new patterns by hand on drafting film, a very time consuming and exacting process. They also continued on with other mug ideas for light relief.

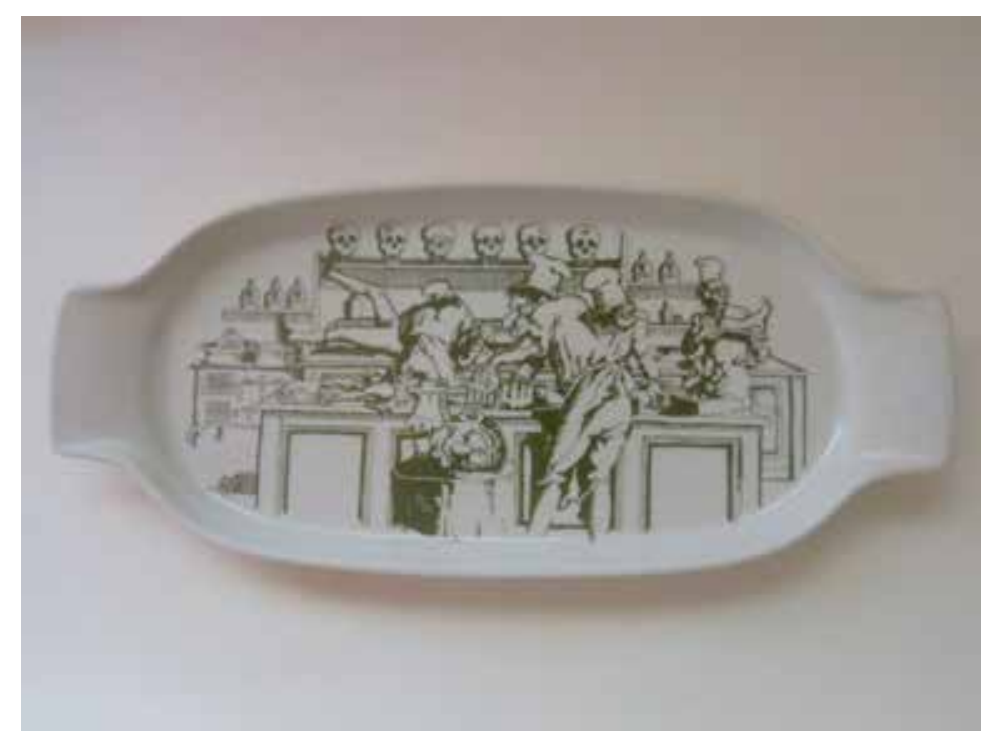

'Cordon Kitchenware', a one-off design by lan $\mathrm{McNee}$ 